\title{
Evaluation of Mixed-Phase Cloud Parameterizations in Short-Range Weather Forecasts with CAM3 and AM2 for Mixed-Phase Arctic Cloud Experiment
}

\section{Third Quarter 2007 ARM Metric Report}

June 2007

Shaocheng Xie, James Boyle, and Stephen Klein

Lawrence Livermore National Laboratory

Livermore, California

Xiaohong Liu and Steven Ghan

Pacific Northwest National Laboratory

Richland, Washington

Work supported by the U.S. Department of Energy,

Office of Science, Office of Biological and Environmental Research 


\section{Summary}

Mixed-phase clouds dominate low-level Arctic clouds in cold seasons and have a significant impact on the surface energy budget. However, the treatment of mixed-phase clouds in most current climate models is crude because the detailed microphysical processes involved in mixed-phase clouds are not completely understood, primarily owe to the paucity of cloud observations in the past. Improving mixed-phase cloud parameterizations requires an advanced understanding of cloud and cloud microphysics through carefully planned field studies. By making use of the in-situ data collected from the recent Atmospheric Radiation Measurement Mixed-Phase Arctic Cloud Experiment, we have tested the mixed-phase cloud parameterizations used in the two major U.S. climate models, the National Center for Atmospheric Research Community Atmosphere Model version 3 (CAM3) and the Geophysical Fluid Dynamics Laboratory climate model (AM2), under both the single-column modeling framework and the U.S. Department of Energy Climate Change Prediction Program-Atmospheric Radiation Measurement Parameterization Testbed. An improved and more physically based cloud microphysical scheme for CAM3 has been also tested. The single-column modeling tests were summarized in the second quarter 2007 Atmospheric Radiation Measurement metric report. In the current report, we document the performance of these microphysical schemes in short-range weather forecasts using the Climate Chagne Prediction Program Atmospheric Radiation Measurement Parameterizaiton Testbest strategy, in which we initialize CAM3 and AM2 with realistic atmospheric states from numerical weather prediction analyses for the period when Mixed-Phase Arctic Cloud Experiment was conducted. It is shown that CAM3 significantly underestimates the observed boundary layer mixed-phase clouds and cannot realistically simulate the variations with temperature and cloud height of liquid water fraction in the total cloud condensate based an oversimplified cloud microphysical scheme. In contrast, AM2 reasonably reproduces the observed boundary layer clouds while its clouds contain much less cloud condensate than CAM3 and the observations. The simulation of the boundary layer mixed-phase clouds and their microphysical properties is considerably improved in CAM3 when the new physically based cloud microphysical scheme is used. The new scheme also leads to an improved simulation of the surface and top of the atmosphere longwave radiative fluxes in CAM3. It is shown that the Bergeron-Findeisen process, i.e., the ice crystal growth by vapor deposition at the expense of coexisting liquid water, is important for the models to correctly simulate the characteristics of the observed microphysical properties in mixed-phase clouds. 


\section{Contents}

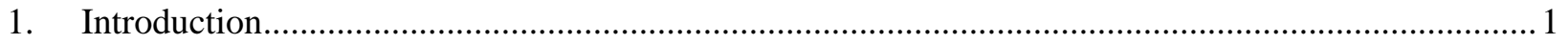

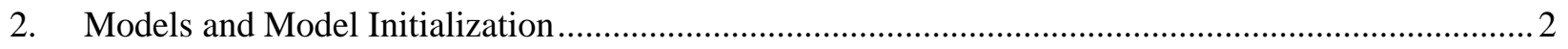

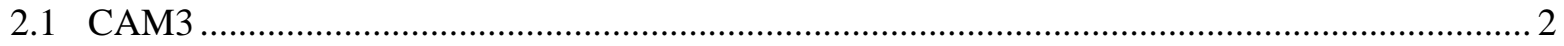

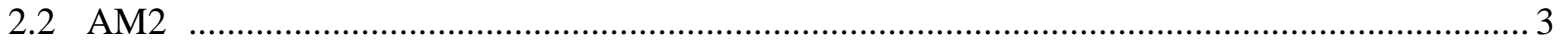

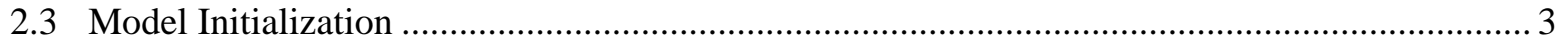

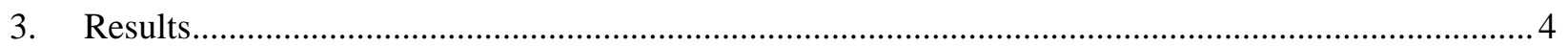

3.1 Characteristics of Clouds Observed from M-PACE ................................................................ 4

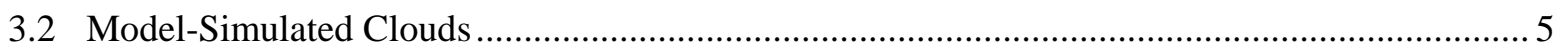

3.3 Cloud Properties in Mixed-Phase Clouds: Model vs. Aircraft Data.......................................... 8

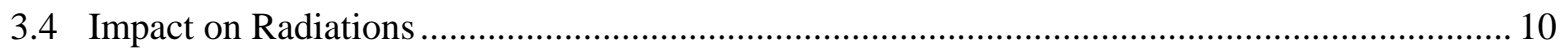

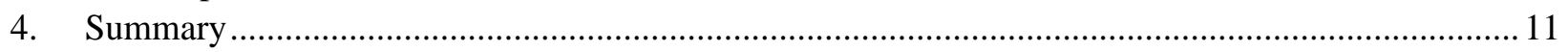

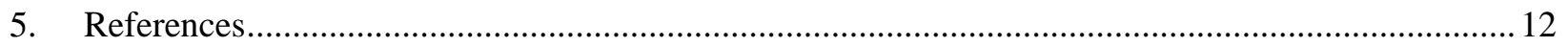

\section{Figures}

1 Time-height cross sections of (a) the ARSCL clouds, (b) CAM3 clouds, (c) AM2 clouds, and (d) CAM3LIU clouds at Barrow during M-PACE. ...................................................................... 4

2 Time series of the total cloud fraction (\%) derived from ARSCL $\left({ }^{*}\right)$ and the models ........................ 6

3 Time-height cross sections of model-produced liquid water mixing ratio $(\mathrm{g} / \mathrm{kg})$............................. 6

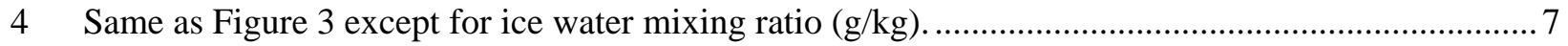

5 Time series of the observed and model-produced cloud liquid water path $\left(\mathrm{g} / \mathrm{m}^{2}\right)$ and ice water

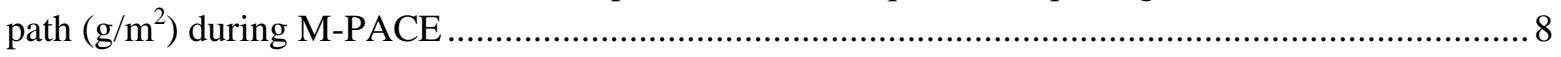

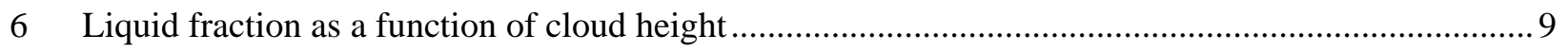

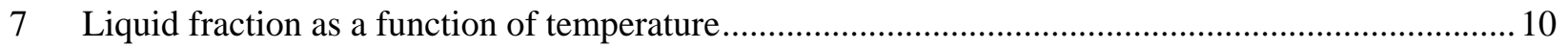

8 Time series of the observed and model-produced (a) surface downwelling longwave radiative fluxes $\left(\mathrm{W} / \mathrm{m}^{2}\right)$ and $(\mathrm{b})$ TOA outgoing longwave radiative fluxes $\left(\mathrm{W} / \mathrm{m}^{2}\right) \ldots \ldots \ldots \ldots \ldots \ldots \ldots . . . . . . . . . . .11$ 


\title{
Evaluation of Mixed-Phase Cloud Parameterizations in Short- Range Weather Forecasts with CAM3 and AM2 for Mixed-Phase Arctic Cloud Experiment
}

\author{
Third Quarter 2007 ARM Metric Report
}

\section{Introduction}

Clouds have a significant impact on the surface energy budget through modulating radiative fluxes. Observations indicate that during cold seasons, mixed-phase clouds dominate low-level Arctic clouds. The radiative properties of mixed-phase clouds are largely determined by their microphysical properties (e.g., cloud liquid water and ice). Thus, accurate representation of microphysical properties of mixedphase clouds is critical for climate models to correctly simulate cloud-radiative effects in the Arctic. Earlier studies showed that the partitioning of cloud water between liquid and ice phases in mixed-phase clouds could have a large impact on the model predicted climate change (Li and Le Treut 1993; Gregory and Morris 1996).

However, the treatment of mixed-phase clouds in most current climate models is often oversimplified because the detailed microphysical processes involved in mixed-phase clouds are not completely understood, primarily owed to the paucity of cloud observations, which is particularly true in the Arctic. As a result, many important microphysical processes in mixed-phase clouds, such as ice nucleation and growth and the complex interaction between the ice and liquid phases of cloud condensate, are not appropriately represented in these models. For example, the latest version of the National Center for Atmospheric Research (NCAR) Community Atmospheric Model (CAM3) still uses a single-moment microphysical scheme that only predicts the mixing ratio of cloud condensate. The number concentration of cloud liquid droplets and ice is specified in CAM3, based on limited observations available in the lower latitudes. The distinction between cloud liquid water and ice is simply assumed as a function of temperature. These simplified and/or non-physically based microphysical parameterizations have largely limited the ability of these climate models to accurately simulate the evolution of mixed-phase clouds and their radiative properties. It is also difficult to represent aerosol-cloud coupling in these models, which requires a prognostic equation for the number concentration of cloud droplets so that the impact of aerosols on the number concentration of cloud droplets can be realistically represented. The aerosolcloud-radiation interaction is one of the key processes and it must be accurately included in climate models.

To improve the representation of mixed-phase clouds in CAM3, we have implemented a physically based microphysical scheme to this model. This new scheme is a double-moment scheme in which both the mixing ratio and number concentration of cloud condensate are predicted according to the physical processes involved in mixed-phase clouds. For example, the new scheme uses a prognostic equation for ice crystal number concentration together with an ice nucleation scheme developed by Liu and Penner (2005). It employs the Rotstayn et al. (2000) scheme to physically calculate the ice crystal growth by vapor deposition at the expense of coexisting cloud liquid water. The effective radius of ice crystals in the new scheme is based on the model-predicted mass and number concentration of ice rather than 
diagnosed as a function of temperature in the default scheme. In our previous Atmospheric Radiation Measurement (ARM) Metric Reports, we have provided a detailed description of this new microphysical scheme and documented its performance based on tests from using the single-column model version of CAM3 (Liu and Ghan 2007; Liu et al. 2007). The single-column model tests showed that the new microphysical scheme produced a more realistic structure of mixed-phase clouds observed during the ARM Mixed-Phase Arctic Cloud Experiment (M-PACE) in comparison with the default microphysical scheme used in CAM3.

In this report, we further evaluate the new scheme in short-range weather forecasts with CAM3 using the U.S. Department of Energy (DOE) Climate Change Predictino Program (CCPP)-ARM Parameterization Testbed (CAPT). CCPP is the DOE Climate Change Prediction Program. The CAPT framework provides a flexible environment for running climate models in numerical weather prediction (NWP) mode. In comparison with testing parameterizations in climate simulations, the CAPT strategy is to initialize climate models with realistic atmospheric states from NWP analyses for a period where a selected field campaign was conducted. In this way, we can make a direct model-observation comparison and link model deficiencies directly with specific atmospheric processes observed during the field campaign. The CAPT approach has been proven as an useful way to understand climate errors and facilitate model parameterization improvements (Phillips et al. 2004; Xie et al. 2004; Boyle et al. 2005, Williamson et al. 2005; Klein et al. 2006). In addition to CAM3, the microphysical scheme used in the National Oceanic and Atmospheric Administration Geophysical Fluid Dynamics Laboratory (GFDL) climate model (AM2) is also tested under CAPT. Data collected from M-PACE are used to evaluate the performance of these microphysical parameterizations in simulating the mixed-phase clouds observed during the field experiment.

\section{Models and Model Initialization}

\subsection{CAM3}

CAM3 is the sixth generation of the NCAR atmospheric general circulation model. The version used in this report is CAM3.1 with its finite volume dynamic core at resolution of $1.9^{\circ} \mathrm{x} 2.5^{\circ}$ in the horizontal and 26 levels in the vertical. Compared to its earlier versions, CAM3 incorporates significant improvements to its physical parameterizations of clouds and radiation. The treatment of cloud microphysics and cloud condensate in CAM3 is based on the prognostic cloud water formulation of Rasch and Kristjansson (1998, hereafter RK98) with modifications made by Zhang et al. (2003). Further improvements for RK98 include separate equations for predicting cloud ice and cloud liquid water, advection of cloud condensate by large-scale circulation, and gravitational settling of cloud ice and liquid particles (Boville et al. 2006). RK98 is a single-moment scheme that only predicts the mixing ratio of cloud condensate. The distinction between liquid and ice phase is made as a function of temperature. The fraction of liquid water in the total condensate is defined as:

$$
\begin{array}{ll}
\mathrm{f}_{\mathrm{l}}=0 & \text { if } \mathrm{T} \leq \mathrm{T}_{\min } \\
\mathrm{f}_{\mathrm{l}}=\left(\mathrm{T}-\mathrm{T}_{\min }\right) /\left(\mathrm{T}_{\max }-\mathrm{T}_{\text {min }}\right) & \text { if } \mathrm{T}_{\min }<\mathrm{T}<\mathrm{T}_{\max } \\
\mathrm{f}_{\mathrm{l}}=1 & \text { if } \mathrm{T} \geq \mathrm{T}_{\max }
\end{array}
$$


where $\mathrm{T}$ is temperature, $\mathrm{T}_{\min }=-40^{\circ} \mathrm{C}$, and $\mathrm{T}_{\max }=-10^{\circ} \mathrm{C}$. Cloud fraction in CAM3 is diagnosed for convective clouds based on convective mass flux and for stratiform clouds based on relative humidity outside of the convective cloud. Other detailed information about CAM3 can be seen in Collins et al. (2006).

A physically based ice microphysical scheme described in Liu and Ghan (2007) is also tested in CAM3. The new scheme is a double-moment scheme in which a prognostic equation is used for ice crystal number concentration together with an ice nucleation scheme developed by Liu and Penner (2005). The ice mixing ratio is still calculated by the modified RK98 scheme described in Boville et al. (2006) but the liquid and ice partitioning is now based on the Rotstayn et al. (2000) scheme to include the Bergeron-Findeisen process - the ice crystal grows by vapor deposition at the expense of the liquid-water droplets because the saturation vapor pressure with respect to ice is lower than with respect to liquid. Another important change is that the effective radius of ice crystals is now based on the model-predicted mass and number concentration of ice rather than diagnosed as a function of temperature in the default model. This will make a closer link between model radiation and cloud properties. The stratiform cloud fraction is calculated using the same RH-based scheme as that in the default model except that ice supersaturation is allowed in the new scheme. This may have impact on cloud fraction when temperature is colder than $-20^{\circ} \mathrm{C}$ at which $\mathrm{RH}$ is computed with respective to ice.

\section{$2.2 \quad$ AM2}

AM2 is the GFDL climate atmospheric model. The model resolution used in this study is $2.0^{\circ} \times 2.5^{\circ}$ in horizontal and 24 levels in vertical. Its cloud microphysical scheme follows Rotstayn (1997) and Rotstayn et al. (2000), in which two separate prognostic equations are used to predict cloud liquid and ice and the liquid/ice partitioning is determined by microphysical processes such as the Bergeron-Findeisen mechanism. This microphysical scheme is a single-moment scheme. Cloud fraction in AM2 is determined by a prognostic cloud fraction scheme developed by Tiedtke (1993). Further details are available from GFDL GAMDT (2004).

\subsection{Model Initialization}

Both CAM3 and AM2 were initialized from the NASA Data Assimilation Office (DAO) analysis data for M-PACE. More information about the DAO analyses is available at http://gmao.gsfc.nasa.gov/. The analysis data were interpolated from the finer-resolution reanalysis grid $\left(0.5^{\circ} \times 0.5^{\circ}\right)$ to the CAM3 or AM2 grid using the procedures described in Boyle et al. (2005). These procedures used a slightly different interpolation approach for each of the dynamic state variables, $\mathrm{u}, \mathrm{v}, \mathrm{T}, \mathrm{q}$ and Ps along with careful adjustments to account for the difference in representation of the earth's topography between the reanalysis and the models. The DAO analyses reasonably captured the temporal evolution and vertical structure of the observed upper-air circulation, temperature, and moisture during M-PACE (not shown). This is important since the observed cloud systems during M-PACE are largely controlled by the synoptic-scale circulation affecting that area as described in Verlinde et al. (2007). 
A series of 5-day forecasts with CAM3 and AM2 are initialized every day at 00Z from these analyses for the entire period of M-PACE. 12-36 hour forecasts from these runs are examined in order to reduce the impact of model spin-up that may occur in the first few hour integrations but still keep the atmospheric states close to the observations so that model errors can be primarily linked to deficiencies in model physics. Results at the model grid point that is closest to the ARM Barrow site are compared with the M-PACE observations.

\section{Results}

\subsection{Characteristics of Clouds Observed from M-PACE}

The M-PACE campaign was conducted during the period from 5 - 22 October 2004 at the ARM North Slope of Alaska site. It provided the most complete set of measurements for arctic clouds and their microphysical properties by using millimeter-wave cloud radars, micropulse lidars, laser ceilometers, and aircrafts (Verlinde et al. 2007). Various types of clouds that often occur in the Arctic during this transition season were observed in the field experiment. Figure 1a shows the time-pressure cross section of observed clouds at Barrow by integrating measurements from ARM cloud radar and other sensors using the Active Remotely-Sensed Clouds Locations (ARSCL) algorithm (Clothiaux et al. 2000). It is seen that Barrow was covered with multilayered stratus clouds in the mid- and low-levels with the cloud top up to $550 \mathrm{hPa}$ for 5 - 8 October, persistent single-layer boundary layer stratocumulus with the cloud top around $850 \mathrm{hPa}$ during the period from 8 to 14 October, and deep prefrontal and frontal clouds (including cirrus) from 15 - 22 October. The temperature range for the single-layer boundary layer clouds is from $-5^{\circ} \mathrm{C} \sim-20^{\circ} \mathrm{C}$, indicating that the clouds are in mixed phase.
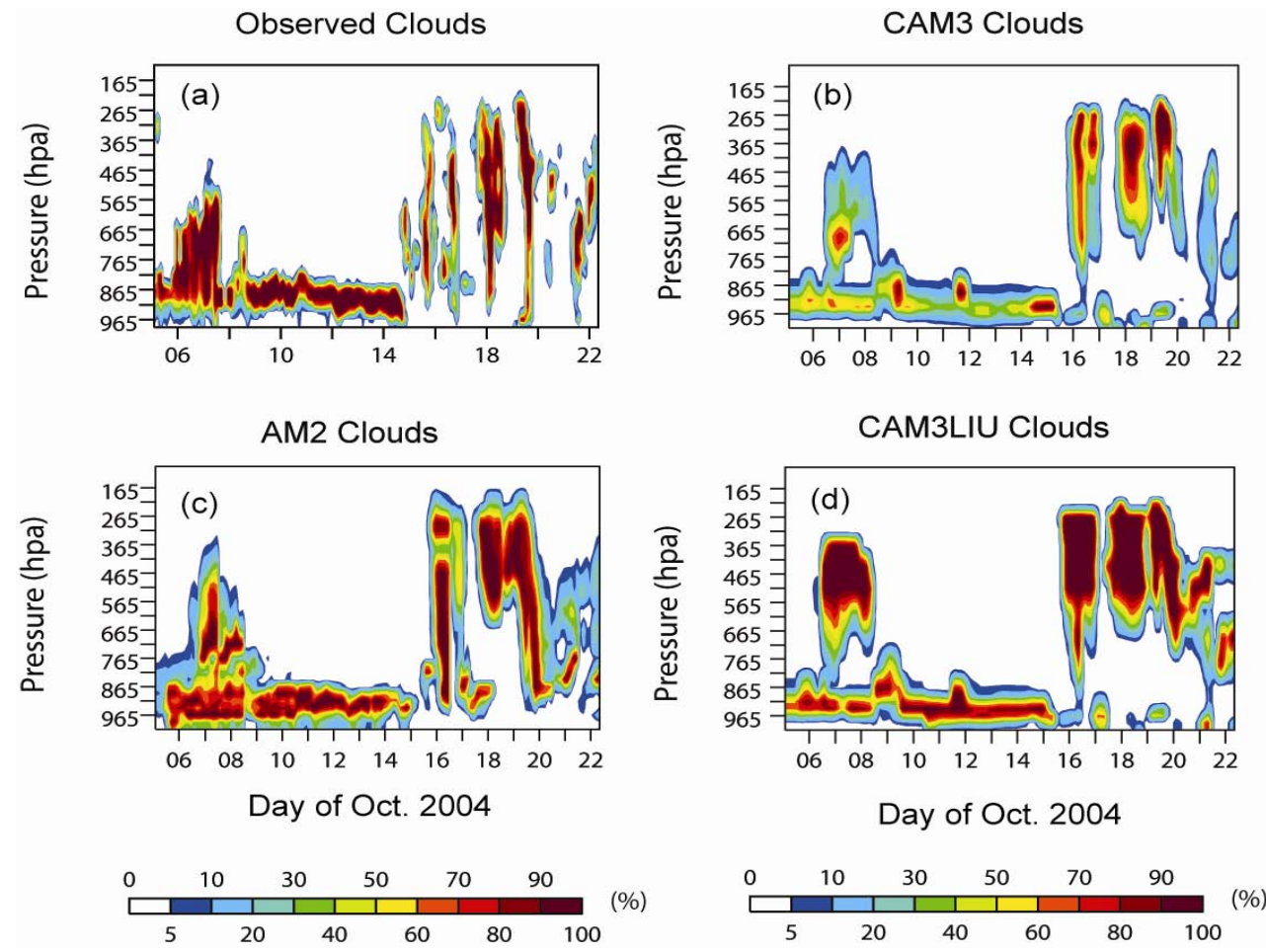

Figure 1. Time-height cross sections of (a) the ARSCL clouds, (b) CAM3 clouds, (c) AM2 clouds, and (d) CAM3LIU clouds at Barrow during M-PACE. 
To get measurements of microphysical properties of these cloud systems, the ARM millimeter cloud radar, micropulse lidars, laser ceilometers, and two instrumented aircrafts were used in the experiment. For the single-layer boundary layer clouds, data collected from both the surface-based remote sensing instruments and the aircrafts revealed the presence of a liquid water layer near cloud top and irregular ice crystals within the cloud layer with precipitating ice beneath the liquid cloud base (McFarquhar et al. 2007). This result is consistent with the findings from other arctic field campaigns (Pinto 1998; Hobbs and Rangno 1998; Curry et al. 2000). The multilayered clouds had a more complicated structure than the single-layer clouds. Up to six liquid cloud layers were detected by the ARM narrow-band lidar and the depth of individual liquid cloud layers varied from 50 to $300 \mathrm{~m}$. Combined both radar and lidar data indicated the existence of precipitating ice with low ice crystal concentration between the layers. These characteristics are similar to those from the in situ measurements by the aircrafts. A detailed summary of the observed clouds during M-PACE can be seen in Verlinde et al. (2007) and McFarquhar et al. (2007). In the following discussion, we examine how well CAM3 and AM2 capture these observed features in the arctic clouds.

\subsection{Model-Simulated Clouds}

Figures 1b, 1c, and 1d show the model-produced clouds at Barrow from CAM3, AM2, and CAM3 with the new ice microphysics (hereafter CAM3LIU), respectively. All the models are able to qualitatively reproduce the cloud types observed during M-PACE, such as the multilayered clouds from 5 - 8 October, the boundary layer clouds from 8 - 14 October, and the frontal deep high clouds from 15 22 October. However, there are considerable differences in detailed structures of the clouds between the observations and the model simulations. For the period 5-14 October, the default CAM3 substantially underestimates the observed multi-layered and single-layer boundary layer clouds. In contrast, AM2 produces the mid- and low-level clouds much larger than CAM3. It is interesting to see that CAM3 with the new ice microphysics produces more realistic single-layer boundary clouds than the default CAM3 while it generates too many mid- and high level clouds which may be related to its allowance of ice supersaturation. One common problem for all the models is that the modeled cloud top and cloud base are lower than the observed for this period. This may be partially related to the coarse vertical resolutions used in these models, which cannot well resolve the observed boundary layer structure. For those deep frontal clouds, the models tend to overestimate the clouds at high levels and underestimate them at midand low levels. The problem with the mid- and low-level clouds is particularly true for the CAM models.

Figure 2 shows a comparison of the total cloud fraction between the models and the observations at Barrow for the period when the multilayered clouds and mixed-phase boundary clouds occurred. The total cloud fraction is calculated from the ARSCL products and the modeled clouds assuming maximum cloud overlap. The observations typically showed a persistent almost $100 \%$ cloud cover during this period except on $7-8$ and 11 October where the cloud cover decreased slightly. Consistent with earlier discussions, CAM3 considerably underestimates the total cloud cover for this period. This problem is significantly reduced in CAM3LIU when the new physically based ice microphysical scheme is used. AM2 also produces a better cloud cover than the default CAM3. It is seen that the clouds produced by the default CAM3 and AM2 show larger temporal variability than the observations, indicating the difficulty in maintaining the persistence of mixed-phase boundary layer clouds in these two models. In contrast, CAM3LIU produces $100 \%$ cloud cover during most of the period, similar to the observations. The model ability to maintain the long life of mixed-phase boundary layer clouds will have large impacts on the surface energy budget in the Arctic as discussed later. 


\section{Total Cloud Amount}

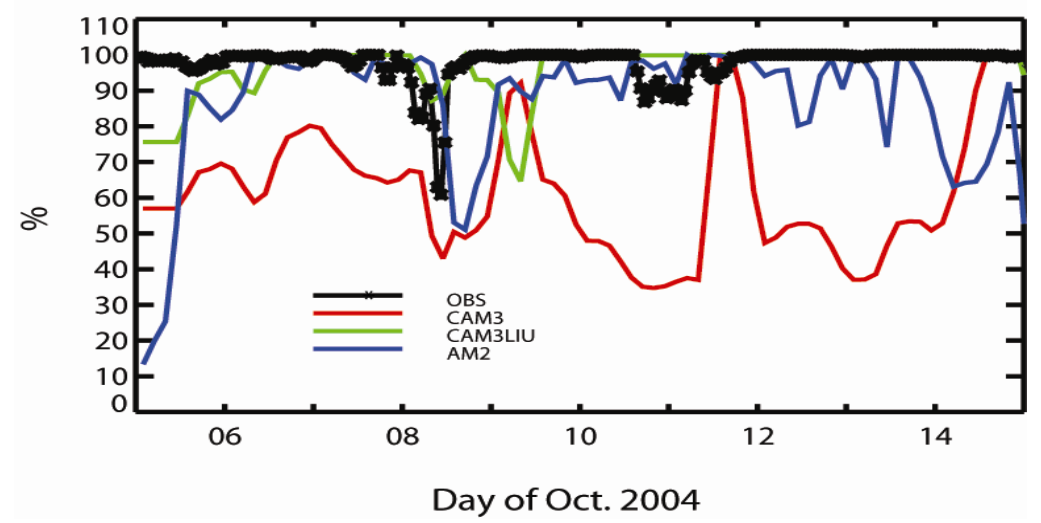

Figure 2. Time series of the total cloud fraction (\%) derived from ARSCL $\left(^{*}\right)$ and the models. Red line is for CAM3, green for CAMLIU, and blue for AM2.

Figures 3a-c show the liquid water mixing ratio produced from these models. The contour lines in Figure 3 are the model produced temperatures, which are around $-5^{\circ} \mathrm{C} \sim-20^{\circ} \mathrm{C}$ for the multi-layered and single-layer boundary layer clouds. One noteworthy feature is that AM2-produced clouds contain much less liquid than CAM3 even though it has much larger cloud fraction as shown in Figure 1. With the new ice microphysics, CAM3LIU produces more liquid for the low-level clouds and less liquid for the midand upper level clouds in comparison with CAM3. For the model-produced ice water mixing ratio (Figure 4), both AM2 and CAM3LIU show significant amount of ice in the multi-layer and boundarylayer clouds and beneath the cloud bases while the default CAM3 shows almost no ice near or beneath the boundary layer cloud bases where temperature is often warmer than its assumed threshold temperature $\left(-10^{\circ} \mathrm{C}\right)$ for ice formation. This is inconsistent with the in situ measurements as we discussed above.
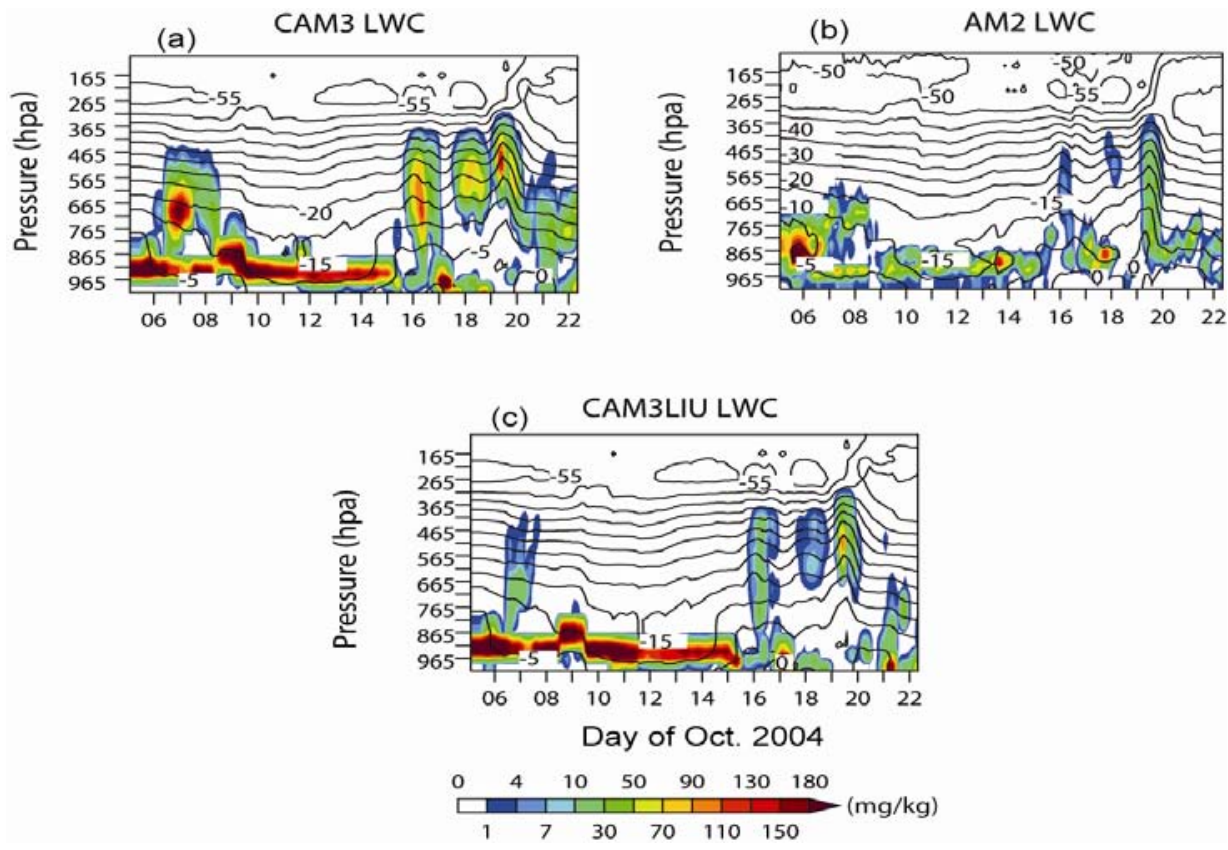

Figure 3. Time-height cross sections of model-produced liquid water mixing ratio (g/kg). (a) CAM3, (b) AM2, and (c) CAM3LIU. The solid lines in the figures are model-simulated temperature. 

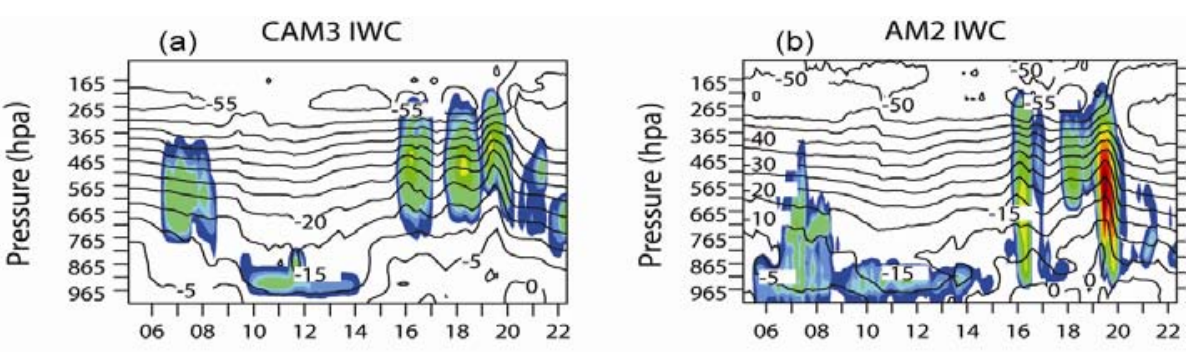

(c) CAMBLIU IWC

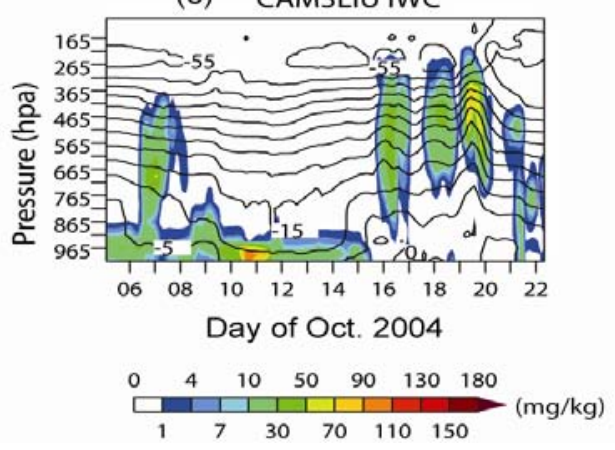

Figure 4. Same as Figure 3 except for ice water mixing ratio $(\mathrm{g} / \mathrm{kg})$.

Figures $5 \mathrm{a}$ and $5 \mathrm{~b}$ show the observed and modeled cloud liquid water path (LWP) and cloud ice water path (IWP) at Barrow, respectively. There are two sources for the observed LWP. One is based on the ARM surface Microwave Radiometer measurements (Turner et al. 2007) and another one is derived from the ARM cloud radar and lidar measurements (Wang 2007). The observed IWP is only available from the radar and lidar retrievals. Note that the radar and lidar retrievals are currently only available for the single-layer boundary layer mixed-phase clouds. The instrument uncertainty is typically within $5 \%$ for LWP and 50\% for IWP. It is seen that the LWPs from these two measurements agree with each other very well for the period when the radar and lidar retrievals are available. CAM3 reasonably reproduces the observed LWP for the single-layer mixed phase clouds even though its cloud amount is significantly smaller than the observations. This is because CAM3 cloud fraction is determined by its large-scale relative humidity rather than its cloud condensate. It is worth noting that, for the range of temperature $5^{\circ} \mathrm{C} \sim-20^{\circ} \mathrm{C}$, the majority of cloud condensate produced in CAM3 will be liquid due to its temperature dependent liquid/ice partitioning. Figure 5b shows that CAM3 produces little ice during this period. One clear problem with CAM3 is that it largely overestimates the observed LWP for the mid- and high level clouds (e.g., October 7, 16, $18-20$ ). This problem is significantly reduced with the use of the new ice microphysical scheme as shown in CAM3LIU, which also predicts a reasonable LWP for the boundary layer clouds. The LWP in AM2 is considerably smaller than CAM3 and the observations for the boundary layer clouds. For which, it is surprising to see that there is not much ice produced by AM2, neither, given the fact that AM2 produces much more boundary layer clouds than CAM3. Once again this indicates that AM2-produced clouds contain much less cloud condensate than CAM3 for the boundary layer clouds. One possible explanation is that cloud condensate in AM2 grows much faster to precipitable size and falls out of the model atmosphere compared to CAM3. Consistent with this, AM2 generates larger surface precipitation rates than CAM3 during this period. The average surface precipitation rates over the period from October $9-14$ are $0.7 \mathrm{~mm} /$ day for AM2 and $0.42 \mathrm{~mm} /$ day for CAM3. Figure 5b shows that AM2 produces significantly large IWP than CAM3 for the deep frontal clouds. 


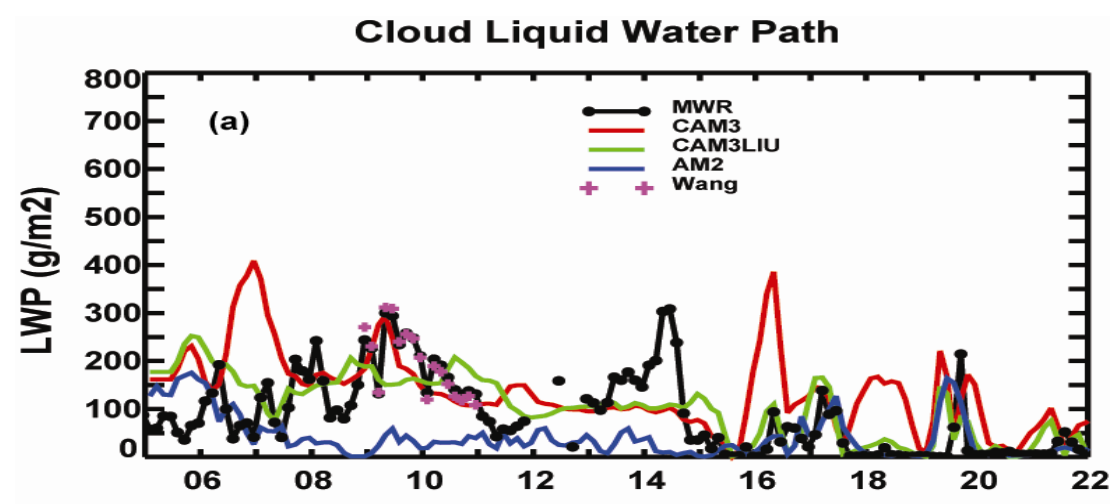

Cloud Ice Water Path

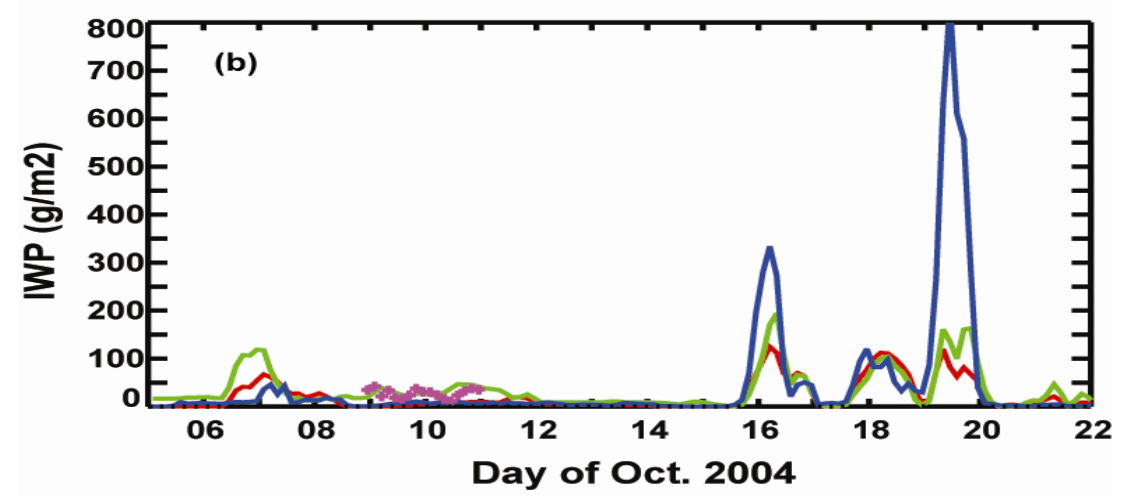

Figure 5. Time series of the observed and model-produced cloud liquid water path $\left(\mathrm{g} / \mathrm{m}^{2}\right)$ and ice water path $\left(\mathrm{g} / \mathrm{m}^{2}\right)$ during M-PACE. The black lines with dots is from Microwave Radiometer data and + is from Wang's radar retrievals. Red lines are for CAM3, green for CAMLIU, and blue for AM2.

\subsection{Cloud Properties in Mixed-Phase Clouds: Model vs. Aircraft Data}

The instrumented aircrafts used in M-PACE provided unique information to understand the microphysical properties in the mixed-phase clouds. Figure 6a displays the liquid fraction $\left(\mathrm{f}_{\mathrm{l}}\right)$ in the total cloud condensate as a function of height measured by the University of North Dakota (UND) Citation from flights on 9-10 October for the single-layer mixed phase clouds. Note that the cloud altitude is normalized from 0 at cloud base to 1 at cloud top. The different color dots in Figure 6a represent data collected from different flights. The aircraft data revealed the dominance of cloud liquid water in the boundary layer mixed-phase clouds with $79 \%$ of cases having $f_{1}>90 \%$. In general, fl increases with height and is larger than $80 \%$ near cloud top. Many data points with low $\mathrm{fl}$ are found in the lower half of the cloud, indicating the presence of significant amounts of ice. The strong liquid layer near cloud top leads to strong cloud--top radiative cooling, which may play an important role in maintaining the persistence of mixed-phase boundary layer clouds (e.g., Pinto 1998). This observed vertical distribution of $\mathrm{f}_{\mathrm{l}}$ is clearly not reproduced by CAM3 in which $\mathrm{fl}$ is determined by temperature. As shown in Figure 6b, more than $90 \%$ of total cloud condensate produced by CAM3 throughout the cloud layer is liquid. In contrast, the observed variation of liquid water fractions with cloud height is reasonably captured by CAM3LIU and AM2 although both models show larger ice component in the upper half of the cloud (Figures 6c-d). 


\section{Boundary Layer Mixed-phase Clouds}
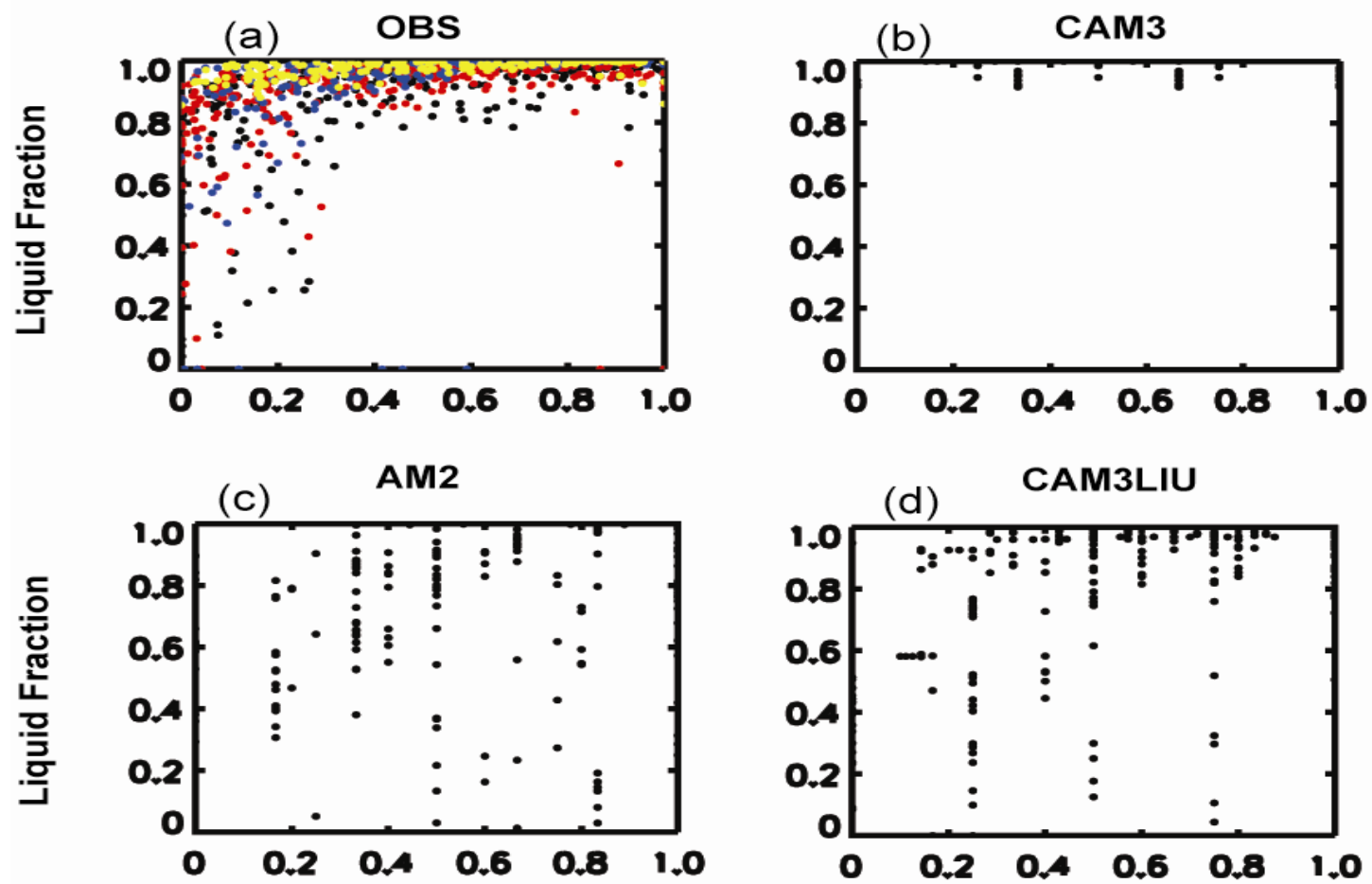

Normalized Height in Clouds

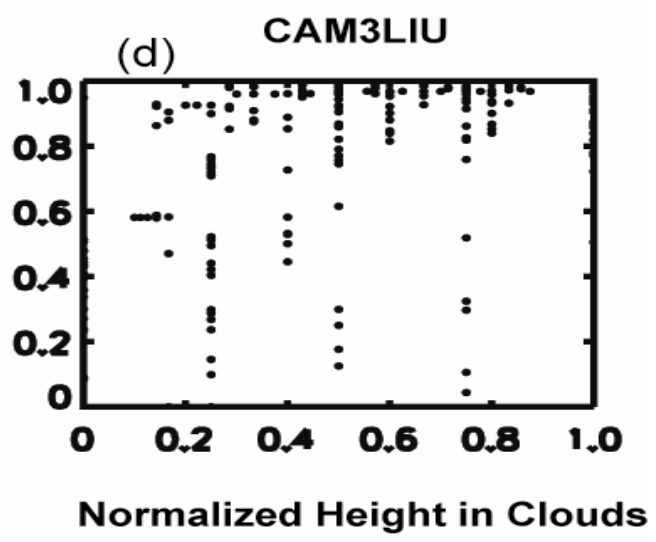

Figure 6. Liquid fraction as a function of cloud height. (a) UND citation data, (b) CAM3, (c) AM2, and (d) CAM3LIU. Different color dots in (a) represent data collected from different flights. Note that the cloud altitude in the figure is normalized from 0 at cloud base to 1 at cloud top.

Figure $7 \mathrm{a}$ shows the measured $\mathrm{f}_{\mathrm{l}}$ as a function of temperature from the same flights as Figure 6a. The measured cloud temperatures during these flights are about between $-16^{\circ} \mathrm{C}$ to $-9^{\circ} \mathrm{C}$. It is seen that there is no clear relationship between $f_{l}$ and temperature in the observations. Significant amounts of liquid and ice co-exist at this temperature range. It is obvious that any temperature based liquid/ice partitioning schemes will fail to reproduce the observed structure, such as the scheme used in CAM3 (see Figure 7b). Once again, AM2 and CAM3LIU reasonably reproduce the observed variation with temperature of $f_{1}$ by including the Bergeron-Findeisen process (Figures 7c-d). This indicates that the Bergeron-Findeisen process is important for the models to correctly capture observed structure of cloud condensate in the mixed-phase clouds. 


\section{Boundary Layer Mixed-phase Clouds}

(a)

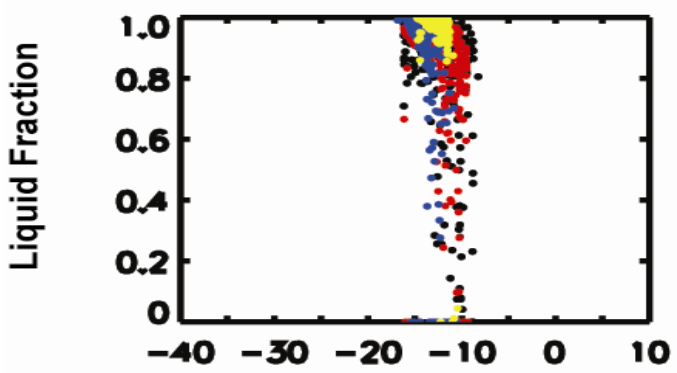

(c)

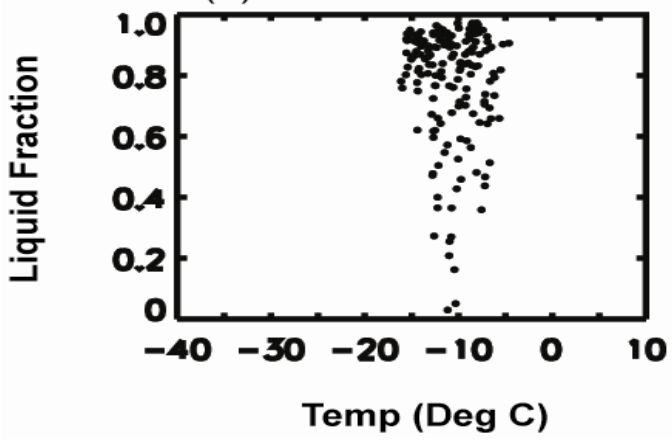

(b)

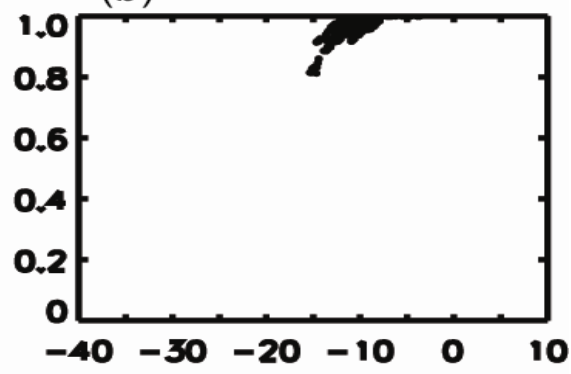

CAM3LIU

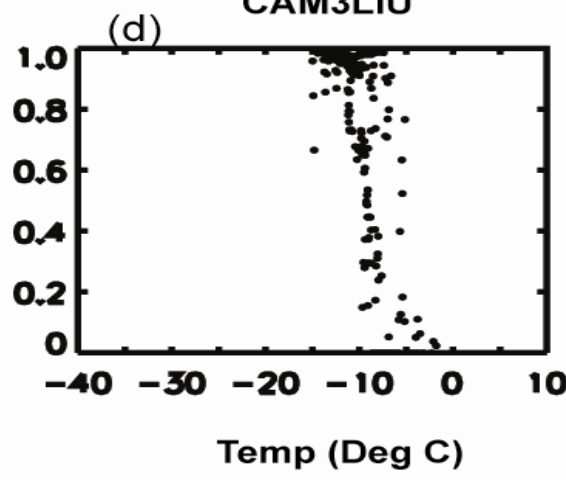

Figure 7. Liquid fraction as a function of temperature. (a) UND citation data, (b) CAM3, (c) AM2, and (d) CAM3LIU. Different color dots in (a) represent data collected from different flights.

\subsection{Impact on Radiations}

Clouds have a significant impact on radiative fluxes. In the Arctic cold seasons, longwave radiation dominates surface and top of the atmosphere (TOA) energy budgets. Figure 8a displays the observed and modeled downwelling longwave radiative fluxes at surface (FLDS) for the period when the multi-layer and single-layer boundary layer clouds were present. The observed FLDS shows a rather weak temporal variability due to the presence of persistent low-level clouds. The observed FLDS is significantly underestimated by CAM3, due primarily to its underestimation of the low-level clouds as shown in Figures 1 and 2. In addition, CAM3 shows much larger temporal variation in FLDS than the observations, consistent with the larger temporal variation in its produced cloud cover (Figure 2). These problems are largely reduced in CAM3LIU, which only slightly overestimates the observed FLDS for the period 10 -14 October. The overestimation may be related to the lower cloud base in CAM3LIU. AM2 shows a better simulation of FLDS than CAM3. Its produced FLDS agrees well with the observations for most of the period while it significantly underestimates the observations on Days 9, 13, and 14 due to the smaller cloud fraction produced on these days (Figure 2). The averaged FLDSs over this period are 284, 264, 291, and $278\left(\mathrm{~W} / \mathrm{m}^{2}\right)$ for the observations, CAM3, CAM3LIU, and AM2, respectively.

Figure $8 \mathrm{~b}$ is the same as Figure 8a except for the outgoing longwave radiative fluxes (OLR) at TOA. The observed TOA radiative fluxes are from satellite measurements. All the models consistently overestimate the observed OLR in the presence of the single-layer boundary layer clouds (9 -14 October). This is related to the underestimation of the clouds and cloud liquid water path during this period as 
discussed earlier. The underestimation of the low-level cloud top in these models may also attribute to this problem. Compared to CAM3, the overestimation is largely reduced in CAM3LIU. It is seen that CAM3LIU considerably underestimate the observed OLR on day 7 when the multi-layered clouds occurred. This is manly because CAM3LIU clouds extend to much higher altitude (300 mb) than the observed ( $550 \mathrm{mb}$ ) (see Figure 1).

Surface Downwelling Longwave Radiation Fluxes

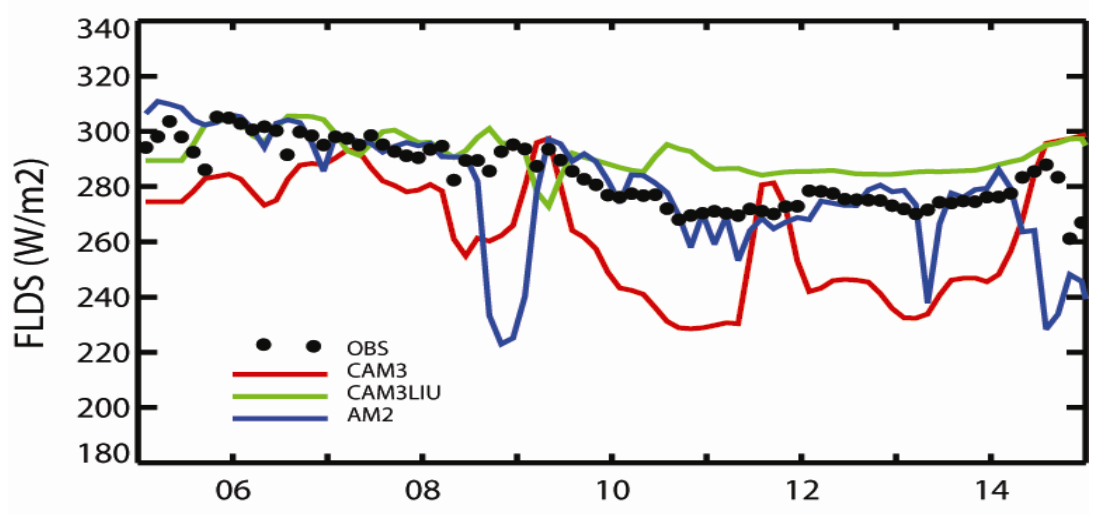

TOA Outgoing Longwave Radiative Fluxes

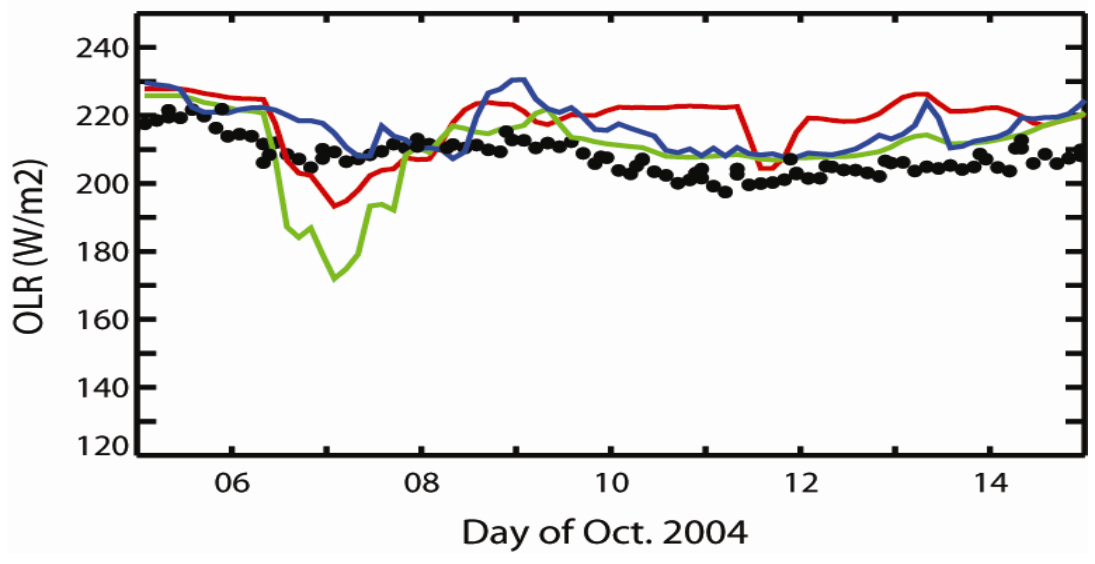

Figure 8. Time series of the observed and model-produced (a) surface downwelling longwave radiative fluxes $\left(\mathrm{W} / \mathrm{m}^{2}\right)$ and (b) TOA outgoing longwave radiative fluxes $\left(\mathrm{W} / \mathrm{m}^{2}\right)$. Black dots are observations. Red lines are for CAM3, green for CAMLIU, and blue for AM2.

\section{Summary}

We have evaluated the mixed-phase cloud parameterizations used in the two major U.S. climate models, the NCAR CAM3 and GFDL AM2, in short-range forecasts under the DOE CCPP-CAPT using the in-situ data collected over the North Slope of Alaska during the ARM M-PACE field experiment. We have shown that both models are able to qualitatively capture the various cloud types observed during the M-PACE when they are initialized with realistic atmospheric conditions from NWP analyses. However, there are significant differences in the simulated cloud fraction and cloud microphysical properties between the two models and between the models and the observations. CAM3 significantly underestimates the observed boundary layer mixed-phase clouds and cannot realistically simulate the 
variations with temperature and cloud height of liquid water fraction in the total cloud condensate based an oversimplified cloud microphysical scheme. It also largely overestimates the liquid water path for mid- and high level clouds. AM2 reasonably reproduces the observed boundary layer clouds while its clouds contain much less cloud condensate than CAM3 and the observations. The simulation of the boundary layer mixed-phase clouds and their microphysical properties is considerably improved in CAM3 when a more physically based cloud microphysical scheme (i.e., CAM3LIU) is used. This new scheme also leads to an improved simulation of the surface and top of the atmosphere longwave radiative fluxes. This study has shown that the Bergeron-Findeisen process, i.e., the ice crystal growth by vapor deposition at the expense of coexisting liquid water, is important for the models to correctly simulate the characteristics of the observed microphysical properties in mixed-phase clouds.

Acknowledgments. We gratefully thank Drs. G. McFarquhar, D. Turner, Z. Wang, C. Long, and P. Minnis for making the M-PACE field campaign data available for our use. We thank all the LLNL CAPT team members for their valuable comments on this work. This research was performed under the auspices of the U.S. Department of Energy's ARM Program by the University of California, Lawrence Livermore National Laboratory, under contract W-7405-Eng-48.

\section{References}

Byran, A, P Rasch, J Hack, and J McCaa. 2006. "Representation of clouds and precipitation processes in the Community Atmosphere Model Version 3 (CAM3).” Journal of Climate, 19:2184 - 2198.

Boyle, JS, D Williamson, R Cedereall, M Fiorino, J Hnilo, J Olson, T Phillips, G Potter, and S Xie. 2005. "Diagnosis of Community Atmospheric Model 2 (CAM2) in numerical weather forecast configuration at the Atmospheric Radiation Measurement sites.” Journal of Geophysical Research, 110(D15S15) doi:10.1029/2004JD005042.

Clothiaux, EE, TP Ackerman, GG Mace, KP Moran, RT Marchand, MA Miller, and BE Martner. 2000. "Objective determination of cloud heights and radar reflectivities using a combination of active remote sensors at the ARM CART sites.” Journal of Applied Meteorology, 39:645-665.

Collins, WD, PJ Rasch, BA Boville, JJ Hack, JR McCaa, DL Williamson, BP Briegleb, CM Bitz, L Shian-Jiann, and Z Minghua. 2006. "The formulation and atmospheric simulation of the Community Atmosphere Model Version 3 (CAM3).” Journal of Climate, 19:2144-2161.

Curry, JA, PV Hobbs, MD King, DA Randall, P Minnis, GA Isaac, JO Pinto, T Uttal, A Bucholtz, DG Cripe, H Gerber, CW Fairall, TJ Garrett, J Hudson, JM Intrieri, C Jakob, T Jensen, P Lawson, D Marcotte, L Nguyen, P Pilewskie, A Rangno, DC Rogers, KB Strawbridge, FPJ Valero, AG Williams, and D Wylie. 2000. "FIRE Arctic Clouds Experiment. Overview of Arctic cloud and radiation properties.” Bulletin of the American Meteorological Society 81:5-29.

The GFDL Global Atmospheric Model Development Team. 2004. "The new GFDL global atmosphere and land model AM2-LM2: Evaluation with prescribed SST simulations.” Journal of Climate, 17:46414673. 
Gregory, D, and D Morris. 1996. "The sensitivity of climate simulations to the specification of mixed phase clouds.” Climate Dynamics, 12:641-651.

Hobbs, PV, and AL Rangno. 1998. "Microstructures of low and middle-level clouds over the Beaufort sea.” Quarterly Journal of the Royal Meteorolgocial Society, 124:2035-2071.

Li, Z-X, and H Le Treut. 1992. "Cloud-radiation feedbacks in a general circulation model and their dependence on cloud modeling assumptions.” Climate Dynamics, 7:133-139.

Liu, X, and JE Penner. 2005. “Ice nucleation parameterization for global models.” Meteorologische Zeitschrift, 14(4)499-514.

Liu, X, and S Ghan. 2007. “Mixed-phase cloud microphysics for global climate models.” First Quarter 2007 ARM Metric Report, available from http://www.arm.gov/science/metrics.stm.

Liu, X, S Ghan, and S Xie. 2007. "Evaluation of mixed-phase cloud microphysics parameterizations with the NCAR single column climate model (SCAM) and ARM observations.” Second Quarter 2007 ARM Metric Report, available from http://www.arm.gov/science/metrics.stm.

McFarquhar, GM, and co-authors. 2007. "Ice properties of single layer boundary clouds during the Mixed-Phase Arctic Cloud Experiment (MPACE): Part I: Observations.” submitted to Journal of Geophysical Research.

Phillips, TJ, and 9 co-authors. 2004. "Evaluating parameterizations in GCMs: Climate simulation meets weather prediction.” Bulletin of the American Meteorological Society, 85:1903-1915.

Pinto, JO. 1998. “Autumnal mixed-phase cloudy boundary layers in the Arctic.” Journal of Atmospheric Science, 55:2016-2038.

Rasch, PJ, and JE Kristjánsson. 1998. "A comparison of the CCM3 model climate using diagnosed and predicted condensate parameterizations.” Journal of Climate, 11:1587-1614.

Rotstayn, LD. 1997. "A physical based scheme for the treatment of stratiform clouds and precipitation in large-scale models. I: Description and evaluation of the microphysical processes.” Quarterly Journal of the Royal Meteorological Society, 123:1227-1282.

Rotstayn, LD, BF Ryan, and JJ Katzfey. 2000. "A scheme for calculation of the liquid fraction in mixedphase stratiform clouds in large-scale models.” Monthly Weather Review, 128:1070-1088.

Tiedtke, M. 1993. "Representation of clouds in large-scale models." Monthly Weather Review, 121:3040- 3061.

Turner, DD, SA Clough, JC Liljegren, EE Clothiaux, K Cady-Pereira, and KL Gaustad. 2007. "Retrieving liquid water path and precipitable water vapor from Atmospheric Radiation Measurement (ARM) microwave radiometers.” IEEE Transactions on Geosciences Remote Sensing, submitted. 
Verlinde, J and Coauthors. 2007. “The Mixed-Phase Arctic Cloud Experiment.” Bulletin of the American Meteorologial Society, 88:205-221.

Wang, Z. 2007. "Refined two-channel microwave radiometer liquid water path retrieval at cold regions by using multiple-sensor measurements.” submitted to IEEE Geoscience and Remote Sensing Letters.

Williamson, DL, and co-authors. 2005. "Moisture and temperature balances at the Atmospheric Radiation Measurement Southern Great Plains Site in forecasts with the Community Atmosphere Model (CAM2).” Journal of Geophysical Research, 110:D15S16, doi:10.1029/2004JD005109.

Xie, S, and 5 co-authors. 2004. "Impact of a revised convective triggering mechanism on Community Atmosphere Model, Version 2, simulations: Results from short-range weather forecasts.” Journal of Geophyscial Research, 109(D14102)doi:10.1029/2004JD004692.

Zhang, M, W Lin, C Bretherton, J Hack, and P Rasch. 2003. “A modified formulation of fractional stratiform condensation rate in the NCAR Community Atmospheric Model (CAM2)." Journal of Geophysical Research, 108(4035)doi:10.1029/2002JD002523. 